\title{
Metabolic syndrome is a sequela of radiation exposure in hypothalamic obesity among survivors of childhood brain tumors
}

\author{
Raven Cooksey, ${ }_{1}^{1}$ Susan Y Wu, ${ }^{2}$ Laura Klesse, ${ }^{3,4}$ Jon D Oden, ${ }^{5}$ Ross E Bland, ${ }^{5}$ \\ Joseph C Hodges, ${ }^{6}$ Lynn Gargan, ${ }^{3}$ Gloria Lena Vega, ${ }_{1}^{3}$ Daniel C Bowers ${ }^{3,4}$
}

Additional material is published online only. To view, please visit the journal online (http://dx.doi.org/10. 1136/jim-2018-000911).

'Dell Children's Medical Center of Central Texas, Austin, Texas, USA

${ }^{2}$ University of California San Francisco, San Francisco,

California, USA

3University of Texas

Southwestern Medical Center, Dallas, Texas, USA

${ }^{4}$ Children's Medical Center of Dallas, Dallas, USA

${ }^{5}$ Northeast Louisiana Cancer Institute, Monroe, Louisiana, USA

${ }^{6}$ Texas Oncology-Longview Cancer Center, Longview, Texas, USA

\section{Correspondence to} Professor Daniel C Bowers, Department of Pediatrics, Dallas, TX 75390, USA; Daniel.Bowers@ utsouthwestern.edu and Professor Gloria Lena Vega, Center for Human Nutrition, Dallas, TX 75390, USA; Gloria.Vega@ utsouthwestern.edu

Accepted 10 November 2018

Published Online First 9 December 2018

\section{ABSTRACT}

Survivors of childhood brain tumors may be at risk for early onset of metabolic syndrome, possibly secondary to surgery and/or radiation exposure. This study examines effects of radiation exposure to hypothalamus-pituitary-adrenal axis (HPA) on metabolic risk among survivors of childhood brain tumors. One hundred forty-two met inclusion criteria; 60 had tumor surgery plus radiation exposure $(\geq 1$ Gray (Gy)) to HPA. The second subgroup of 82 subjects had surgery only and were not exposed to radiation. Both subgroups had survived for approximately 5 years at the time of study. All had clinical evaluation, vital signs, anthropometry, measurement of body composition by dual X-ray absorptiometry and fasting laboratory assays (metabolic panel, insulin, C-peptide, insulin-like growth factor-1, leptin and adiponectin). Body composition data for both subgroups was compared with the National Health and Nutrition Survey (NHANES) subgroup of similar age, gender and body mass index. Cranial surgery was associated with obesity of similar severity in both subgroups. However, survivors exposed to radiation to the HPA also had increased visceral fat mass and high prevalence of growth hormone deficiency and metabolic syndrome. Fat mass alone did not explain the prevalence of the metabolic syndrome in radiation exposure subgroup. Other factors such as growth hormone deficiency may have contributed to metabolic risk. We conclude that prevalence of metabolic syndrome among subjects exposed to hypothalamic radiation was higher than expected from hypothalamic obesity alone. Radiation exposure may exert untoward endocrinopathies due to HPA exposure that worsens metabolic risk. Early screening for metabolic syndrome in this population is indicated.

\section{INTRODUCTION}

Brain tumors are the second most common type of cancer among children younger than 20 years of age. ${ }^{1-3}$ As survival rates for children with brain tumors improve, ${ }^{1}$ increasing attention has turned to the observation that childhood brain tumor survivors are at increased risk for several late effects, including secondary cancers, neurologic deficits, cognitive impairment, hormone

\section{Significance of this study}

What is already known about this subject?

- Brain tumors are the second most common type of cancer among children younger than 20 years of age.

- As survival rates for children with brain tumors improve, increasing attention has turned to the observation that childhood brain tumor survivors are at increased risk for several late effects, including secondary cancers, neurologic deficits, cognitive impairment, hormone deficiencies, growth failure and stroke.

\section{What are the new findings?}

- This study shows that radiation exposure to the hypothalamus in children is associated with hypothalamic obesity.

- Survivors also exposed to radiation of the hypothalamic-pituitary-adrenal axis (HPA) were equally obese to those having cranial surgery only.

- Prevalence of metabolic syndrome among subjects exposed to hypothalamic radiation was higher than expected from hypothalamic obesity alone.

- Prevalence of growth hormone deficiency was higher in subjects exposed to hypothalamic radiation therapy.

How might these results change the focus of research or clinical practice?

- Radiation therapy may exert untoward endocrinopathies due to HPA exposure that worsens metabolic risk.

- Early screening for metabolic syndrome risk factors in this population is indicated.

deficiencies, growth failure and stroke. ${ }^{4-8}$ Risk for developing these late effects has been associated with age at cancer diagnosis, tumor histology, tumor location and radiation exposure, including age at radiation exposure, total dose of radiation and region of brain exposed to cranial radiation. ${ }^{6-8}$

Several studies have demonstrated that childhood acute lymphoblastic leukemia (ALL) 
survivors exposed to cranial radiation have increased prevalence of early onset metabolic syndrome (MetS) ${ }^{9-14}$ The rate and risk factors for MetS among childhood brain tumor survivors are not known. The syndrome is characterized by three of the following modifiable factors: central obesity, elevated triglycerides, low high-density lipoprotein (HDL), elevated blood pressure or fasting hyperglycemia. In the general population, a diagnosis of MetS is strongly associated with premature heart disease, type 2 diabetes mellitus, cardiovascular mortality as well as increased all-cause mortality. ${ }^{1516}$ Whereas leukemia therapy uses $12-18$ Gray (Gy) cranial radiation and intrathecal methotrexate, brain tumor therapy often includes a several-fold higher dose of cranial radiation, although often radiation exposure fields are limited to specific regions of the brain.

The objectives of this study were to compare the metabolic sequela of exposure to radiation versus no exposure among childhood brain tumor survivors. Effects of radiation exposure on body composition, risks for MetS and prevalence of MetS were quantified.

\section{METHODS}

\section{Patient population}

All subjects or their guardians signed informed consent to participate in the study.

One hundred and forty-five of 171 screened patients were consented but only 142 were able to participate in a case-control study conducted at the Comprehensive Neuro-Oncology Long-Term Follow-Up Clinic at UT Southwestern Medical Center and Children's Medical Center of Dallas. Subjects were included into the study if they were aged $<18$ years at the time of cancer diagnosis, they had at least 1 year after completion of treatment, which could have included any combination of surgery, chemotherapy or radiation, if they were aged between 5 and 21 years at the time of study. The reason for inclusion of subjects $>1$ year after completing therapy for their tumor was to allow sufficient time for the neuroendocrine and immune systems to reach steady state. Subjects were excluded if they had a diagnosis of type 1 diabetes mellitus, co-diagnosis of neurofibromatosis type 1 or diagnosis of craniopharyngioma. Pregnant women were excluded as well as subjects not willing to comply with all study requirements. Subjects taking steroids were not included.

\section{Study design}

This cross-sectional study included measurement of height, weight and waist circumference at the level of the umbilicus and superior iliac crests in the standing position, vital signs (blood pressure, heart rate), Tanner pubertal staging, fasting laboratory assays (metabolic panel, insulin, C-peptide, insulin-like growth factor-1 (IGF-1), leptin, and adiponectin). Body mass index (BMI, $\mathrm{kg} / \mathrm{m}^{2}$ ) and BMI $\mathrm{z}$ scores (based on US growth charts found on the following website http:// www.cdc.gov/growthcharts) were calculated. The Paffenbarger Physical Activity Survey, ${ }^{9}$ and the MEDFICTS diet recall survey ${ }^{10}$ were also administered. Radiation exposure plans were reviewed by physicians from the Department of Radiation Oncology at the University of Texas Southwestern Medical Center. Body composition was determined by dual X-ray absorptiometry (DXA). The scanning was performed with a Hologic Discovery W QDR Series scanner (Hologic, Bedford, Massachusetts, USA). Data were analyzed with APEX System software (V.13.4.2), detailed previously. ${ }^{11}$

\section{Metabolic parameters}

Metabolic risk factors and MetS were defined according to the 2007 International Diabetes Federation (IDF) criteria for children and adolescents 10 years of age or older. ${ }^{12}$ Briefly, central obesity was identified as a waist circumference $\geq 90$ th percentile for age and gender for minors $<15$ years whereas for adolescents $>16$ years, the cut point for waist circumference was $\geq 80 \mathrm{~cm}$ for females and $\geq 90 \mathrm{~cm}$ for males. At-risk plasma triglyceride levels were defined as $\geq 150 \mathrm{mg} / \mathrm{dL}$, low HDL $\leq 40 \mathrm{mg} / \mathrm{dL}$ for men and women $<15$ years and males $>16$ years. Women $>16$ years had a cut point of $\leq 50 \mathrm{mg} / \mathrm{dL}$. High blood pressure was defined as systolic $\geq 130 \mathrm{~mm} \mathrm{Hg}$ or diastolic $\geq 85 \mathrm{~mm} \mathrm{Hg}$ for age $\geq 10$ years and at the 90th percentile for age, gender and height for individuals $<10$ years. Fasting hyperglycemia was defined as fasting glucose $\geq 100 \mathrm{mg} / \mathrm{dL}$ or known type 2 diabetes mellitus. This approach has been employed by numerous investigators and is particularly useful in younger subjects as it evaluates criteria such as blood pressure and waist circumference using age, gender and height-based percentiles. ${ }^{13} 141718$

Insulin resistance was assessed using the homeostasis model assessment of insulin resistance (HOMA-IR), as described by Matthew et al ${ }^{19}$ which uses a one-time fasting measurement of insulin and glucose to characterize insulin sensitivity and $\beta$-cell function. The formula for HOMA-IR is: $\frac{\text { glucose }\left(\frac{\mathrm{mg}}{\mathrm{dL}}\right) \times \text { insulin }\left(\frac{\mathrm{mU}}{\mathrm{L}}\right)}{405}$. HOMA-IR is of particular value in populations at risk for developing insulin resistance as it can identify individuals who have not yet developed fasting hyperglycemia, but are compensating with increased insulin production. Insulin resistance was defined as a HOMA-IR value $\geq 2.5$ in prepubertal children (Tanner stage I) ${ }^{2021}$ and a HOMA-IR value $\geq 4.0$ in pubertal subjects (Tanner stage $\geq \mathrm{II}) .^{22} 23$

Patients diagnosed with MetS were subsequently referred to the endocrinology service to a hospital-based weight loss programme.

\section{Referent population}

A subset of the NHANES III population of minors consisting of 1878 subjects, henceforth designated referent population, was selected from the 1999 to 2006 NHANES III database published in the Centers for Disease Control and Prevention (CDC) website. The referent population was in the age range of 5-20 years and comprised $63 \%$ males and $37 \%$ females of similar age to the cancer survivor population of the current study. The referent population had anthropometry, body composition analysis done by DXA, measurement of plasma lipids and lipoprotein cholesterol. The methods employed in acquiring the referent data are similar to those employed in the current study and are detailed in the CDC website manual of procedures. The data obtained are de-identified and in the public domain therefore, there was no requirement for IRB approval to use the data in the current study.

The data of body composition from the referent population were employed primarily to evaluate the degree of 
obesity of the subjects with cranial tumors compared with the population at large. The data on levels of plasma lipids and lipoprotein cholesterol were employed to determine degree of dyslipidemia in the study subjects.

\section{Analytical methods}

Plasma triglycerides and total and lipoprotein cholesterol were measured after precipitation of non-HDL lipoproteins by polyanion reagents; a colorimetric assay was employed for total cholesterol and triglyceride measurement using standard laboratory procedures. Hormone levels were measured by immunoassays as previously detailed. ${ }^{24}$ Briefly, peptide hormones were measured using immunoassay kits (Linco Research, St. Charles, Missouri, USA).

\section{Statistical analysis}

Two-tailed t-tests, and $\mathrm{X}^{2}$ analysis were used to compare predictive variables between subjects with and without exposure to hypothalamic-pituitary-adrenal (HPA) radiation. The body composition of both subgroups was compared with the referent NHANES subgroup by analysis of variance. A p value $\leq 0.05$ was considered to be statistically significant. NCSS 9 was employed for the statistical analyses (https://www.ncss.com/).

\section{RESULTS}

\section{Subject characteristics}

All subjects participating in the study had undergone treatment for brain tumors. Among those meeting inclusion criteria for the study, 60 subjects were exposed to at least 1 Gy radiation to the hypothalamus and were thus considered to have received measurable radiation to the HPA. The remainder 82 subjects were treated with standard of care therapy (surgery, \pm chemotherapy, \pm radiation therapy to sites that did not include the HPA).

Approximately $42 \%$ of patients studied were exposed to radiation fields that included the hypothalamus (exposed) and the remainder were not exposed (table 1). Both study groups had similar ages at the time of study and there were no significant differences in the survival time post-therapy (table 1). However, subjects who were exposed to hypothalamic radiation were significantly older $(p=0.001)$ at the age of diagnosis than those who were not exposed. The majority of the subgroup that were exposed to radiation had a diagnosis of medulloblastoma, whereas the majority of the subgroup that did not have radiation exposure had a diagnosis of pilocytic astrocytoma (table 1). About half the study population was non-Hispanic, white race.

\section{Body composition and anthropometry}

Body composition and anthropometric parameters were first compared between the two study groups, that is, the subgroup exposed to radiation and the group not exposed to radiation. Both study groups had similar BMI, waist circumference, per cent body fat and lean masses (table 2). However, the BMI $z$-score showed a significant trend for lower level in the radiation exposure group $(p=0.014)$. Most of the subjects who were exposed to hypothalamic radiation were in Tanner stage III and IV, whereas the group not exposed to radiation were Tanner stage I and II. There were no significant differences in body composition (total body fat, lean mass and bone mineral

\begin{tabular}{|c|c|c|}
\hline \multirow[b]{2}{*}{ Criteria } & \multicolumn{2}{|c|}{ Hypothalamic radiation } \\
\hline & Exposed & Not Exposed \\
\hline Number of subjects & 60 & 82 \\
\hline \multirow[t]{2}{*}{ Males (\%) } & 60.0 & 52.4 \\
\hline & \multicolumn{2}{|l|}{ Median (IQRs) } \\
\hline Age at study evaluation (years) & $14.1(12.6,15.4)$ & $11.9(9.9,13.0)$ \\
\hline Survival time (years) & $4.5(3.5,5.5)$ & $6.3(4.3,7.4)$ \\
\hline Age at diagnosis (years) & $7.2(5.7,9.0)^{*}$ & $4.9(3.6,5.6)$ \\
\hline \multicolumn{3}{|l|}{ Diagnosis (\% of total) } \\
\hline Medulloblastoma & $40.0 \dagger$ & 2.4 \\
\hline Germinoma & $13.3+$ & 0.0 \\
\hline Pilocytic astrocytoma & $11.7 \dagger$ & 50.0 \\
\hline Ependymoma & $13.3+$ & 2.4 \\
\hline Atypical teratoid rhabdoid tumor & 5.0 & 1.2 \\
\hline Other & $16.7 \dagger$ & 43.9 \\
\hline $\begin{array}{l}\text { Radiation plus chemotherapy } \\
\text { therapy }(\%)\end{array}$ & $78.3 \dagger$ & 0.0 \\
\hline \multicolumn{3}{|l|}{ Race (\%) } \\
\hline White & 55 & 53.7 \\
\hline Black & 15 & 11.0 \\
\hline Hispanic & 30 & 26.8 \\
\hline Other & 0 & 8.5 \\
\hline
\end{tabular}

*Significantly different from group not exposed to radiation treatment. $\mathrm{P}=0.001$; two-tailed $\mathrm{t}$-test.

tSignificantly different from group not exposed to radiation treatment. $P<0.01 ; X^{2}$ test.

content) between the group receiving hypothalamic radiation and those not exposed to radiation (table 2). However, there were significant differences in visceral fat $(\mathrm{p}=0.002)$ between the two groups. Those who were exposed to hypothalamic radiation had a higher visceral fat content while the subcutaneous abdominal fat content was similar $(p=0.20)$ between those exposed to radiation and the group not exposed.

The body composition of the two study groups also were compared with the respective measures of the reference NHANES population. Compared with the reference population, the brain tumor survivors had significantly higher body fat $(\mathrm{p}<0.001)$ expressed as $\%$ of total mass, lower lean mass $(p=0.001)$ and a higher fat/lean mass ratios $(p=0.001)$ (table 2). Their total per cent body fat mass was above the 85thpercentile for sex and age compared with the referent NHANES III subpopulation (see online supplementary table 1). Brain tumor survivors also had higher truncal fat $(\mathrm{p}=0.001)$ and appendicular fat mass $(p=0.001)$ but lower appendicular lean mass $(\mathrm{p}=0.001)$ compared with the referent population (table 2).

\section{Metabolic phenotypes}

Patients exposed to radiation that included the hypothalamus had significantly higher HOMA-IR $(p=0.03)$ (table 3$)$ than those who were not exposed to radiation to the HPA. Levels of plasma IGF-1 were lower $(\mathrm{p}=0.013)$ in the exposed group compared with the group that was not exposed to hypothalamic radiation therapy. There were no significant differences in levels of adiponectin $(p=0.387)$, leptin $(p=0.791)$, plasma lipids ( $\mathrm{p}=0.07-0.415)$ and blood pressure $(\mathrm{p}=0.829)$ between the two groups (table 3). Compared with the referent population, child survivors of hypothalamic tumors did not have 
Table 2 Body composition and anthropometry

\begin{tabular}{|c|c|c|c|c|c|}
\hline & \multicolumn{3}{|c|}{ Brain tumor survivors (BTS) } & \multicolumn{2}{|c|}{$\begin{array}{l}\text { NHANES III } \\
\text { Reference population }\end{array}$} \\
\hline & \multirow{2}{*}{$\begin{array}{l}\text { Radiation exposure to } \\
\text { the HPA } n=60 \\
\text { Median (IQRs) }\end{array}$} & \multicolumn{2}{|c|}{$\begin{array}{l}\text { No radiation exposure to the HPA } \\
n=82\end{array}$} & \multicolumn{2}{|l|}{$\mathrm{n}=1878$} \\
\hline & & & $\begin{array}{l}P \text { value RE vs } \\
\text { no } R^{*}\end{array}$ & Median (IQRs) & $\begin{array}{l}\text { TP value for } \\
\text { comparisons to BTS }\end{array}$ \\
\hline Body mass index & $19.6(17.6,21.1)$ & $20.4(19.3,21.9)$ & 0.51 & $21.0(20.9,21.3)$ & 0.36 \\
\hline Body mass index z-score & $0.43(-0.24,0.8)^{*}$ & $0.79(0.55,1.1)$ & 0.014 & - & \\
\hline Waist circumference $(\mathrm{cm})$ & $76(71,83) \dagger$ & $79(74,82) \dagger$ & 0.95 & $74.2(73.8,74.6)$ & $<0.001$ \\
\hline \multicolumn{6}{|c|}{ Body composition (\% of total body mass) } \\
\hline Body fat & $38.1(31.2,39.8) \dagger$ & $33.6(30.6,35.9) \dagger$ & 0.15 & $24.2(23.6,24.8)$ & $\leq 0.001$ \\
\hline Lean mass & $58.6(57.2,65.4)^{*} \dagger$ & $63.0(60.6,65.8) \dagger$ & 0.015 & $73.0(72.4,73.6)$ & $\leq 0.001$ \\
\hline Bone mineral content & $2.9(2.8,3.1) \dagger$ & $3.1(2.9,3.4) \dagger$ & 0.29 & $3.6(3.6,3.6)$ & $\leq 0.001$ \\
\hline Body fat/lean mass ratio & $0.64(0.48,0.69) \dagger$ & $0.52(0.47,0.60) \dagger$ & 0.16 & $0.34(0.32,0.35)$ & $\leq 0.001$ \\
\hline Truncal fat & $15.7(12.9,17.7) \dagger$ & $13.6(11.2,15.8) \dagger$ & 0.23 & $8.8(8.6,9.1)$ & $\leq 0.001$ \\
\hline Appendicular fat mass & $19.0(16.2,19.8) \dagger$ & $17.2(16.0,19.2) \dagger$ & 0.18 & $2.7(2.6,2.8)$ & $\leq 0.001$ \\
\hline Appendicular lean mass & $24.4(23.3,27.1) \dagger$ & $26.9(24.4,28.0) \dagger$ & 0.43 & $32.9(32.6,33.3)$ & $\leq 0.001$ \\
\hline \multicolumn{6}{|c|}{ Abdominal fat ( $\%$ of total body mass) } \\
\hline Subcutaneous abdominal fat & $7.74(5.21,8.44)$ & $6.95(5.21,7.64)$ & 0.20 & - & \\
\hline Visceral fat & $2.07(1.79,2.17)^{*}$ & $1.57(1.26,1.82)$ & 0.002 & - & \\
\hline
\end{tabular}

*Significantly different from the brain tumor survivors who did not have radiation exposure to the HPA.

tSignificantly different from the reference NHANES group.

HPA, hypothalamus-pituitary-adrenal axis; RE, radiation exposure.

markedly altered levels of plasma lipids and lipoprotein cholesterol, although there were significant increases in plasma triglycerides $(p=0.001)$ and some reduction in HDL cholesterol levels $(p=0.001)$ (table 3$)$.

\section{Prevalence of metabolic risk factors and metabolic syndrome}

Patients exposed to radiation that included the HPA had a higher prevalence of some of the metabolic risk factors than the group that did not have radiation exposure to the
HPA (table 4). Importantly, they were more likely to have a higher prevalence of elevated triglycerides $(p=0.02)$, history of growth hormone deficiency $(p=0.001)$ and treatment for the deficiency $(p=0.001)$ than the group that did not have exposure to HPA radiation.

Among subjects exposed to radiation, 3.8\% had MetS and had history of treatment for growth hormone deficiency while $11.2 \%$ had MetS but had no history of treatment for growth hormone deficiency.

Table 3 Metabolic characteristics

\begin{tabular}{|c|c|c|c|c|c|}
\hline & \multicolumn{3}{|c|}{ Brain tumor survivors (BTS) } & \multirow{2}{*}{\multicolumn{2}{|c|}{$\begin{array}{l}\text { NHANES III } \\
\text { Reference population } \\
n=1878\end{array}$}} \\
\hline & \multirow{2}{*}{$\begin{array}{l}\text { Radiation exposure to } \\
\text { the HPA } n=60 \\
\text { Median (IQRs) }\end{array}$} & \multicolumn{2}{|c|}{$\begin{array}{l}\text { No radiation exposure to the HPA } \\
\mathrm{n}=82\end{array}$} & & \\
\hline & & & $\begin{array}{l}\text { *P value } \\
\text { RE vs no RE }\end{array}$ & Median (IQRs) & tP value vs $B T S$ \\
\hline Glucose (mg/dL) & $80(78,83)$ & $78(76,81)$ & 0.14 & - & \\
\hline HOMA-IR $\ddagger(\%)$ & $0.93(0.71,1.2)^{*}$ & $0.78(0.66,92)$ & 0.03 & - & \\
\hline C-peptide (ng/mL) & $1.53(1.24,1.89)$ & $1.37(1.11,1.67)$ & 0.10 & - & \\
\hline IGF-1 (ng/mL) & $162(138,194)^{*}$ & $226(182,261)$ & 0.01 & - & \\
\hline Adiponectin $(\mu \mathrm{g} / \mathrm{mL})$ & $13.5(10.0,16.7)$ & $11.3(9.8,13.1)$ & 0.39 & - & \\
\hline Leptin (ng/mL) & $9.3(5.7,16.3)$ & $9.5(5.3,15.3)$ & 0.79 & - & \\
\hline Triglycerides (mg/dL) & $84(73,101) \dagger$ & $76(69,89) \dagger$ & 0.07 & $64(62,65)$ & $<0.001$ \\
\hline Non-HDL cholesterol (mg/dL) & $101(96,119) \dagger$ & $102(97,110) \dagger$ & 0.18 & $99(98,101)$ & $<0.001$ \\
\hline HDL cholesterol (mg/dL) & $50(44,54) \dagger$ & $50(48,54) \dagger$ & 0.42 & $56(55,56)$ & $<0.001$ \\
\hline Systolic blood pressure $(\mathrm{mm} \mathrm{Hg})$ & $111(109,114) \dagger$ & $113(110,117) \dagger$ & 0.83 & $108.7(108,109)$ & $<0.001$ \\
\hline Diastolic blood pressure $(\mathrm{mm} \mathrm{Hg})$ & $65(64,66) \dagger$ & $65(64,67) \dagger$ & 0.31 & $62(61,62)$ & $<0.001$ \\
\hline
\end{tabular}

*Significantly different from group not exposed to radiation therapy.

tSignificantly different from reference NHANES group.

¥Geometric means.

HDL, high-density lipoprotein; HOMA-IR, homeostasis model assessment of insulin resistance; HPA, hypothalamus-pituitary-adrenal axis; IGF-1, insulin-like growth factor-1. 
Table 4 Prevalence of metabolic risk factors and metabolic syndrome

\begin{tabular}{|c|c|c|c|}
\hline \multirow{2}{*}{$\begin{array}{l}\text { Metabolic parameter (\% of } \\
\text { subgroup) }\end{array}$} & \multicolumn{2}{|c|}{ Hypothalamic radiation } & \multirow[b]{2}{*}{$P$ value } \\
\hline & Exposed & Not Exposed & \\
\hline Metabolic syndrome & $15.0^{*}$ & 4.9 & 0.03 \\
\hline $\begin{array}{l}\text { Metabolic syndrome treated for } \\
\text { growth hormone deficiency }\end{array}$ & 3.8 & NA & \\
\hline $\begin{array}{l}\text { Metabolic syndrome not treated } \\
\text { for growth hormone deficiency }\end{array}$ & 11.2 & NA & \\
\hline \multicolumn{4}{|c|}{ Prevalence of metabolic risk factors (\%) } \\
\hline $\begin{array}{l}\text { Waist circumference }>\text { gender- } \\
\text { specific }\end{array}$ & 27.4 & 32.5 & 0.51 \\
\hline Elevated fasting glucose & 0.0 & 1.2 & 0.29 \\
\hline Triglyceride $>150 \mathrm{mg} / \mathrm{dL}$ & $25.0^{*}$ & 8.6 & 0.02 \\
\hline $\begin{array}{l}\text { High-density lipoprotein } \\
\text { cholesterol< }<0 \text { mg/dL }\end{array}$ & 25.0 & 14.6 & 0.12 \\
\hline $\begin{array}{l}\text { Systolic blood pressure }>130 \mathrm{~mm} \\
\mathrm{Hg}\end{array}$ & 9.7 & 15.7 & 0.29 \\
\hline $\begin{array}{l}\text { History of growth hormone } \\
\text { deficiency }(\%)\end{array}$ & $40.7^{*}$ & 3.7 & $\leq 0.001$ \\
\hline $\begin{array}{l}\text { Treated for growth hormone } \\
\text { deficiency }(\%)\end{array}$ & $37.3^{*}$ & 2.5 & $\leq 0.001$ \\
\hline
\end{tabular}

*Significantly different from group not exposed to radiation therapy; $\mathrm{X}^{2}$ test. $N A$, not applicable for comparisons since subjects were not treated for growth hormone deficiency.

Subgroup analysis was carried out comparing metabolic features of subjects exposed to radiation who also were treated for growth hormone deficiency to those subjects who had no radiation exposure (table 5). Significant differences were noted for insulin resistance parameters (fasting glucose and HOMA-IR) between the two subgroups. All other parameters were similar.

\section{DISCUSSION}

This study demonstrates that MetS is more prevalent in children with brain tumors who are exposed to radiation

Table 5 Comparison of metabolic features in subjects exposed to radiation and treated with growth hormone with subjects not exposed to radiation nor treated with growth hormone

\begin{tabular}{|c|c|c|c|}
\hline & \multicolumn{2}{|c|}{ Hypothalamic radiation } & \multirow[b]{3}{*}{$P$ value } \\
\hline & $\begin{array}{l}\text { Exposed (plus } \\
\text { growth hormone } \\
\text { treatment) }\end{array}$ & $\begin{array}{l}\text { Not Exposed (no } \\
\text { growth hormone } \\
\text { treatment) }\end{array}$ & \\
\hline & \multicolumn{2}{|l|}{ Mean (SD) } & \\
\hline Glucose (mg/dL) & $86(8)$ & $78(9)$ & $>0.001$ \\
\hline HOMA-IR* $(\%)$ & $1.05(0.42,1.8)$ & $0.69(0.52,1.0)$ & 0.03 \\
\hline C-peptide* (ng/mL) & $1.4(1.1,1.7)$ & $1.9(1.4,2.6)$ & 0.26 \\
\hline IGF-1* (ng/mL) & $156(121,170)$ & $194(159,289)$ & 0.63 \\
\hline Adiponectin* ( $\mu \mathrm{g} / \mathrm{mL})$ & $13.2(10.1,17.3)$ & $14.1(6.4,18.4)$ & 0.67 \\
\hline Leptin* (ng/mL) & $10.5(5.7,21.7)$ & $10.0(4.4,20.3)$ & 0.67 \\
\hline Triglycerides (mg/dL) & $105(57)$ & $87(48)$ & 0.19 \\
\hline HDL cholesterol (mg/dL) & $54(16)$ & $54(14)$ & 1.0 \\
\hline Systolic blood pressure $(\mathrm{mm} \mathrm{Hg})$ & $116(12)$ & $114(13)$ & 0.50 \\
\hline $\begin{array}{l}\text { Diastolic blood pressure }(\mathrm{mm} \\
\mathrm{Hg})\end{array}$ & $66(8)$ & $65(8)$ & 0.61 \\
\hline
\end{tabular}

*Medians (IQRs).

HDL, high-density lipoprotein; HOMA-IR, homeostasis model assessment of insulin resistance; IGF-1, insulin-like growth factor-1. of the HPA compared with those who are not exposed to radiation of HPA. This study further shows that there is no difference in the degree of obesity between the children exposed to radiation versus those not exposed to radiation of HPA. The two cohorts of children with brain tumors were equally obese compared with the reference population. Thus, obesity per se cannot completely explain the prevalence of the MetS in the group exposed to radiation. Of interest, there are significant differences in visceral fat content in the subgroup exposed to radiation versus those not exposed to radiation. As expected, children exposed to radiation of the HPA also have a high prevalence of growth hormone deficiency. An inverse association between visceral fat mass and growth hormone has been reported in adults. Furthermore, the prevalence of MetS is higher among the obese children untreated for growth hormone deficiency compared with those treated. Thus, in this population, it would appear the growth hormone deficiency may exert an effect on prevalence of MetS beyond the contribution of total obesity alone.

\section{Hypothalamic obesity}

Hypothalamic obesity is defined as an unmanageable type of obesity that develops in relation to inherited or acquired hypothalamic dysfunction. The obesity results from a variety of dysfunctions in the hypothalamus characterized by disruption of satiety and hunger control, ${ }^{25}$ genetic abnormalities in the hypothalamus, ${ }^{26}$ hypothalamic lesions or trauma, ${ }^{27}$ cerebral aneurysms, ${ }^{28}$ inflammation ${ }^{29}$ or cancer treatment therapies such as radiotherapy. ${ }^{30}$ Several reports support the contention that children undergoing surgery for brain tumors have a high prevalence of hypothalamic obesity. ${ }^{31}$ In addition, this type of obesity has been reported in survivors of cranial radiotherapy, leukemia and brain tumors. ${ }^{32}$ Chemotherapy and other antineoplastic therapies also contribute to the obesity phenotype in cancer survivors. ${ }^{33}$ Hypothalamic obesity is also prevalent in children that have had neurosurgery or radiation therapy of craniopharyngiomas and astrocytomas. ${ }^{34}$ These interventions are known to cause dysregulation of insulin secretion, loss of sensitivity to leptin and impaired activity of the sympathetic nervous system. ${ }^{35}$

In the current study, both radiation exposed and not exposed patients exhibited a hypothalamic obesity phenotype. Those not exposed to radiation had a milder metabolic sequela than those patients receiving radiation exposure. Nonetheless, both groups of patients had acquired obesity most likely related to injury to the hypothalamus due to the tumor and its treatment.

It is also important to note that there were marked differences in the ratio of body fat-to-lean mass in both radiation exposed and not exposed children. The fat mass was higher in the patients exhibiting hypothalamic obesity and the lean mass was lower. Thus, there were no marked differences in the average BMI compared with the reference group. This important observation needs further documentation with MRI methods to quantify muscle mass and fat mass directly. It would be of importance to determine whether hypothalamic obesity in survivors of cranial tumors exhibit an obesity phenotype similar to 'sarcopenic obesity'. If so, assessment of muscle functionality also would be necessary. 
A unique feature of the obesity phenotype in the group exposed to radiation was a higher visceral fat content than the group not exposed. The radiation exposed group also had higher insulin resistance than the group not exposed to radiotherapy. Some studies suggest that abnormal regional fat distribution, and visceral fat in particular, is associated with insulin resistance. ${ }^{36-38}$

Subcutaneous fat has been identified as an expandable fat depot that has the capacity to buffer excess body fat. In contrast, visceral fat expansion is seemingly associated with insulin resistance, inflammation, dyslipidemia and ectopic fat deposition. It is possible that these two depots vary in the degree of plasticity. In the current study, the patients treated with radiation therapy tended to have a non-significant expansion of the subcutaneous fat depot while the visceral depot was clearly expanded. Although it is tempting to speculate that the latter is causally related to the metabolic risk, it is also equally plausible that a failure of the expansion of subcutaneous fat could have contributed to the metabolic risks. Further studies are required to investigate both possibilities.

\section{Growth hormone deficiency}

Growth hormone deficiency was more prevalent in children undergoing exposure to radiation compared with those not having the exposure. Growth hormone deficiency is a well-known sequalae among brain tumor survivors and childhood ALL following exposure to radiation ${ }^{39}$ and has been reported in association with MetS in adults. ${ }^{40}$ Growth hormone, IGF-I and insulin coordinately participate in the regulation of substrate utilization in intermediary metabolism and in the regulation of tissue growth. ${ }^{41}$ The patients who were exposed to radiation therapy in the current study were being treated for growth hormone deficiency and they had significantly lower levels of IGF-I. Still, they had metabolic abnormalities associated with the hormone deficiency suggesting that therapy had not restored metabolic homeostasis. Indeed, subgroup analysis of subjects exposed to radiation and treated for growth hormone deficiency revealed that they had higher insulin resistance than subjects not exposed to radiation. The subgroup analysis also revealed similarities between all other metabolic parameters perhaps suggesting that growth hormone treatment mediated some resolution of metabolic alterations, but treatment was still associated with residual insulin resistance abnormalities. Clearly, more studies are needed to determine the role of growth hormone treatment on metabolic alterations in radiation-exposed subjects.

Growth hormone deficiency also could account for the relative increase of visceral fat depot without significant expansion of the subcutaneous fat depot in the radiation exposed group compared with the group that was not exposed. It is possible that the growth hormone imbalance contributed to diminished adipose tissue plasticity, reduced lipolysis and enhancement of insulin resistance. This would have resulted in increased accumulation of triglyceride in visceral adipose tissue. This notion is partially supported by the inverse association between plasma IGF-I levels and visceral fat mass that has been reported in $\operatorname{men}^{42}$ and by another study ${ }^{43}$ in which treatment of growth hormone deficiency resulted in reduced visceral fat. It would be instructive to measure visceral and subcutaneous fat depots by MRI in subjects with hypothalamic obesity before and during treatment with growth hormone to determine the efficacy of therapy in those that had radiation exposure versus those that did not.

\section{Metabolic syndrome}

MetS is a clustering of risk factors for cardiovascular disease defined mostly by metabolic alterations in blood glucose, plasma lipids and associated with central obesity and hypertension. ${ }^{44}$ The syndrome also has been shown to be prevalent in cancer survivors ${ }^{45} 46$ and its frequency is seemingly related to the various types of treatment used. A high prevalence of MetS has been reported in association with a number of treatment modalities of various cancers including surgery, ${ }^{4748}$ radiation exposure,${ }^{49}$ chemotherapy ${ }^{50}$ and hormonal therapy. ${ }^{47}$

In the current study, it is likely that MetS resulted from a combination of radiotherapy to the HPA and ensuing endocrinopathies such as growth hormone deficiency. Subjects exposed to radiation fields that included the HPA exhibited higher prevalence of dyslipidemia and higher HOMA-IR than their counterparts not exposed to hypothalamic radiation exposure. Multiple studies demonstrate that other endocrinopathies, beyond growth hormone deficiency, follow radiation treatment for brain tumors. ${ }^{51-55}$

Survivors of childhood brain tumors may require a detailed neuroendocrine evaluation to identify abnormalities contributing to alterations in metabolism and body composition. The subjects participating in this study were not taking steroids during the study. Evaluations of thyroid function and adrenal insufficiency were not part of the required study evaluations. However, whereas the reported prevalence of thyroid hormone and growth hormone insufficiency among this population are approximately 50\%, it is therefore standard clinical practice to routinely evaluate thyroid function (free T4 and thyroid-stimulating hormone) and growth hormone secretion (IGF-1, IGFPB-3 to be confirmed with provocative growth hormone stimulation testing) following cranial radiation exposure. This was the clinical practice for all patients in this study. Adrenal insufficiency is much less common after cranial radiation (approximately 3\%) and isolated adrenal insufficiency in the absence of thyroid hormone or growth hormone insufficiency is exceptionally rare. Therefore, asymptomatic individuals are not routinely screened for adrenal insufficiency.

In the current study, there was also the subgroup of subjects not exposed to radiation that had a lower prevalence of MetS than the subjects exposed to radiation. Compared with the NHANES reference population, these subjects were obese. They also had a higher ratio of fat/ lean mass and elevated metabolic parameters compared with NHANES reference population. In these subjects, not presenting with growth hormone deficiency, it is possible that the metabolic alterations resulted from obesity.

It is also noteworthy that the unexposed group presented with a younger age of diagnosis of cancer tumors and a longer survival time compared with those exposed to radiation. Some additional studies are required to determine whether onset of MetS risks is delayed in subjects with 
cranial tumors not exposed to radiation during treatment compared with those exposed to radiation. ${ }^{56-58}$

\section{Current considerations}

This study demonstrates that survivors of childhood brain tumors who have been exposed to radiation to the hypothalamus are at risk of MetS. Furthermore, radiation exposure of the hypothalamus may be causally related to the metabolic sequela of growth hormone deficiency, MetS and increased visceral fat mass. These metabolic complications impart a high risk of type 2 diabetes mellitus, hypertension and cardiovascular disease, which may have substantial implications for these relatively young cancer survivors. These findings have important implications for screening childhood brain tumor survivors at risk of hypothalamic injury for features of MetS. This view is consistent with current recommendations for identification and treatment of cancer-free, pediatric cases at risk for MetS. ${ }^{59}$ It is also equally compelling to focus future research on elucidation of the mechanism of metabolic syndrome in survivors of childhood brain tumors to gain insight into improved treatment approaches.

Contributors All authors meet one or more criteria for coauthorship, that is, substantial contributions to the conception or design of the work, or the acquisition, analysis or interpretation of data; drafting the work or revising it critically for important intellectual content; final approval of the version published. Agreement to be accountable for all aspects of the work in ensuring that questions related to the accuracy or integrity of any part of the work are appropriately investigated and resolved.

Funding Funding for this project was provided by Wipe Out Kids' Cancer, the Children's Cancer Fund of Dallas and a grant from the Doris Duke Charitable Foundation to UTSW and UT-STAR (NIH/NCATS Grant Number UL1TR000451).

Disclaimer This content is solely the responsibility of the authors and does not necessarily represent the official views of the National Institutes of Health or other funding sources.

Competing interests None declared.

Ethics approval The Institutional Review Board of the University of Texas Southwestern Medical Center and the Simmons Cancer Center Protocol Review and Monitoring Committee approved and monitored this study.

Provenance and peer review Not commissioned; externally peer reviewed.

\section{REFERENCES}

1 Gurney JG, Wall DA, Jukich PJ, et al. The contribution of nonmalignant tumors to CNS tumor incidence rates among children in the United States. Cancer Causes Control 1999;10:101-5.

2 Altekruse SF KC, Krapcho M, Neyman N, Aminou R, Waldron W, et al. eds. SEER Cancer Statistics Review, 1975-2007.

3 Ries LAG SM, Gurney JG, Linet M, et al. Bunin GR Cancer Incidence and Survival among Children and Adolescents: United States SEER Program 19751995. Bethesda, MD: National Cancer Institute, SEER Program, 1999.

4 Gurney JG, Kadan-Lottick NS, Packer RJ, et al. Endocrine and cardiovascular late effects among adult survivors of childhood brain tumors: Childhood Cancer Survivor Study. Cancer 2003;97:663-73.

5 Zebrack BJ, Gurney JG, Oeffinger K, et al. Psychological outcomes in long-term survivors of childhood brain cancer: a report from the childhood cancer survivor study. J Clin Oncol 2004;22:999-1006.

6 Packer RJ, Gurney JG, Punyko JA, et al. Long-term neurologic and neurosensory sequelae in adult survivors of a childhood brain tumor: childhood cancer survivor study. J Clin Oncol 2003;21:3255-61.

7 Bowers DC, Liu Y, Leisenring W, et al. Late-occurring stroke among long-term survivors of childhood leukemia and brain tumors: a report from the Childhood Cancer Survivor Study. J Clin Oncol 2006;24:5277-82.

8 Armstrong GT, Liu Q, Yasui Y, et al. Long-term outcomes among adult survivors of childhood central nervous system malignancies in the Childhood Cancer Survivor Study. J Natl Cancer Inst 2009;101:946-58.
9 Ainsworth BE, Leon AS, Richardson MT, et al. Accuracy of the College Alumnus Physical Activity Questionnaire. J Clin Epidemiol 1993;46:1403-11.

10 Kris-Etherton P, Eissenstat B, Jaax S, et al. Validation for MEDFICTS, a dietary assessment instrument for evaluating adherence to total and saturated fat recommendations of the National Cholesterol Education Program Step 1 and Step 2 diets. J Am Diet Assoc 2001;101:81-6.

11 Neeland IJ, Grundy SM, Li X, et al. Comparison of visceral fat mass measurement by dual-X-ray absorptiometry and magnetic resonance imaging in a multiethnic cohort: the Dallas Heart Study. Nutr Diabetes 2016;6:e221.

12 Zimmet $\mathrm{P}$, Alberti KG, Kaufman $\mathrm{F}$, et al. The metabolic syndrome in children and adolescents - an IDF consensus report. Pediatr Diabetes 2007;8:299-306.

13 Butte NF, Comuzzie AG, Cole SA, et al. Quantitative genetic analysis of the metabolic syndrome in Hispanic children. Pediatr Res 2005;58:1243-8.

14 Cruz ML, Goran MI. The metabolic syndrome in children and adolescents. Curr Diab Rep 2004;4:53-62.

15 Wilson PW, D'Agostino RB, Parise $\mathrm{H}$, et al. Metabolic syndrome as a precursor of cardiovascular disease and type 2 diabetes mellitus. Circulation 2005; 112:3066-72.

16 Rutter MK, Meigs JB, Sullivan LM, et al. Insulin resistance, the metabolic syndrome, and incident cardiovascular events in the Framingham Offspring Study. Diabetes 2005;54:3252-7.

17 Pietilä S, Mäkipernaa A, Sievänen $\mathrm{H}$, et al. Obesity and metabolic changes are common in young childhood brain tumor survivors. Pediatr Blood Cancer 2009;52:853-9.

18 Li C, Ford ES, Mokdad AH, et al. Recent trends in waist circumference and waist-height ratio among US children and adolescents. Pediatrics 2006;118:e1 390-e1398.

19 Matthews DR, Hosker JP, Rudenski AS, et al. Homeostasis model assessment: insulin resistance and beta-cell function from fasting plasma glucose and insulin concentrations in man. Diabetologia 1985;28:412-9.

20 Kurtoğlu S, Hatipoğlu N, Mazıcıoğlu M, et al. Insulin resistance in obese children and adolescents: HOMA-IR cut-off levels in the prepubertal and pubertal periods. J Clin Res Pediatr Endocrinol 2010;2:100-6.

21 Yin J, Li M, Xu L, et al. Insulin resistance determined by Homeostasis Model Assessment (HOMA) and associations with metabolic syndrome among Chinese children and teenagers. Diabetol Metab Syndr 2013;5:71.

22 Calcaterra V, Klersy C, Muratori T, et al. Prevalence of metabolic syndrome (MS) in children and adolescents with varying degrees of obesity. Clin Endocrinol 2008;68:868-72.

23 Reinehr T, Andler W. Changes in the atherogenic risk factor profile according to degree of weight loss. Arch Dis Child 2004;89:419-22.

24 Vega GL, Chandalia M, Szczepaniak LS, et al. Metabolic correlates of nonalcoholic fatty liver in women and men. Hepatology 2007;46:716-22.

25 Bray GA, Gallagher TF. Manifestations of hypothalamic obesity in man: a comprehensive investigation of eight patients and a reveiw of the literature. Medicine 1975;54:301-30.

26 Farooqi S, O'Rahilly S. Genetics of obesity in humans. Endocr Rev 2006;27:710-8

27 Lustig RH, Post SR, Srivannaboon K, et al. Risk factors for the development of obesity in children surviving brain tumors. J Clin Endocrinol Metab 2003;88:611-6

28 Bereket A, Kiess W, Lustig RH, et al. Hypothalamic obesity in children. Obes Rev 2012;13:780-98.

29 Schur EA, Melhorn SJ, Oh SK, Sk 0, et al. Radiologic evidence that hypothalamic gliosis is associated with obesity and insulin resistance in humans. Obesity 201523 2142-8.

30 Sklar CA, Mertens AC, Walter A, et al. Changes in body mass index and prevalence of overweight in survivors of childhood acute lymphoblastic leukemia: role of cranial irradiation. Med Pediatr Oncol 2000;35:91-5.

31 Wang KW, Fleming A, Johnston DL, et al. Overweight, obesity and adiposity in survivors of childhood brain tumours: a systematic review and meta-analysis. Clin Obes 2018:8:55-67.

32 Oeffinger KC, Mertens AC, Sklar CA, et al. Obesity in adult survivors of childhood acute lymphoblastic leukemia: a report from the Childhood Cancer Survivor Study. J Clin Oncol 2003;21:1359-65.

33 Teixeira JF, Maia-Lemos PD, Cypriano MD, et al. The influence of antineoplastic treatment on the weight of survivors of childhood cancer. J Pediatr 2016 92:559-66.

34 Müller HL, Bueb K, Bartels U, et al. Obesity after childhood craniopharyngiomaGerman multicenter study on pre-operative risk factors and quality of life. Klin Padiatr 2001;213:244-9.

35 Guran T, Turan S, Bereket A, et al. The role of leptin, soluble leptin receptor, resistin, and insulin secretory dynamics in the pathogenesis of hypothalamic obesity in children. Eur J Pediatr 2009;168:1043-8. 
36 Tchoukalova YD, Votruba SB, Tchkonia T, et al. Regional differences in cellular mechanisms of adipose tissue gain with overfeeding. Proc Natl Acad Sci U SA 2010;107:18226-31.

37 Preis SR, Massaro JM, Robins SJ, et al. Abdominal subcutaneous and visceral adipose tissue and insulin resistance in the Framingham heart study. Obesity 2010;18:2191-8.

38 McLaughlin T, Lamendola C, Liu A, et al. Preferential fat deposition in subcutaneous versus visceral depots is associated with insulin sensitivity. J Clin Endocrinol Metab 2011;96:E1756-E1760.

39 Follin C, Erfurth EM. Long-Term Effect of Cranial Radiotherapy on PituitaryHypothalamus Area in Childhood Acute Lymphoblastic Leukemia Survivors. Curr Treat Options Oncol 2016;17:50.

40 Johannsson G, Bengtsson BA. Growth hormone and the metabolic syndrome. J Endocrinol Invest 1999;22(5 Suppl):41-6.

41 Møller N, Jørgensen JO, Abildgård N, et al. Effects of growth hormone on glucose metabolism. Horm Res 1991;36 Suppl 1(Suppl 1):32-5.

42 Kunitomi M, Wada J, Takahashi K, et al. Relationship between reduced serum IGF-I levels and accumulation of visceral fat in Japanese men. Int J Obes Relat Metab Disord 2002;26:361-9.

43 Johannsson G, Mårin P, Lönn L, et al. Growth hormone treatment of abdominally obese men reduces abdominal fat mass, improves glucose and lipoprotein metabolism, and reduces diastolic blood pressure. J Clin Endocrinol Metab 1997;82:727-34.

44 Grundy SM. Metabolic syndrome update. Trends Cardiovasc Med 2016;26 364-73.

45 de Haas EC, Oosting SF, Lefrandt JD, et al. The metabolic syndrome in cancer survivors. Lancet Oncol 2010;11:193-203.

46 Talvensaari KK, Lanning M, Tapanainen $\mathrm{P}$, et al. Long-term survivors of childhood cancer have an increased risk of manifesting the metabolic syndrome. J Clin Endocrinol Metab 1996;81:3051-5.

47 Kate A, Kadambari D. Incidence of metabolic syndrome in breast cancer survivors on adjuvant hormonal therapy. J Pharmacol Pharmacother 2016;7:28-30.
48 Meinardi MT, Gietema JA, van der Graaf WT, et al. Cardiovascular morbidity in long-term survivors of metastatic testicular cancer. J Clin Oncol 2000;18:1725-32.

49 Darzy KH, Shalet SM. Hypopituitarism following radiotherapy. Pituitary 2009:12:40-50.

50 Armenian $\mathrm{SH}$, Sun CL, Vase T, et al. Cardiovascular risk factors in hematopoietic cell transplantation survivors: role in development of subsequent cardiovascular disease. Blood 2012;120:4505-12.

51 Constine LS, Woolf PD, Cann D, et al. Hypothalamic-pituitary dysfunction after radiation for brain tumors. N Engl J Med 1993;14:87-94.

52 Cohen LE. Endocrine late effects of cancer treatment. Endocrinol Metab Clin North Am 2005;34:769-89.

53 Gleeson HK, Shalet SM. The impact of cancer therapy on the endocrine system in survivors of childhood brain tumours. Endocr Relat Cancer 2004;11:589-602.

54 Madanat LM, Lähteenmäki PM, Hurme S, et al. Hypothyroidism among pediatric cancer patients: a nationwide, registry-based study. Int J Cancer 2008;122:1868-72.

55 Lustig RH. Hypothalamic obesity: causes, consequences, treatment. Pediatr Endocrinol Rev 2008;6:220-7.

56 Constine LS, Woolf PD, Cann D, et al. Hypothalamic-pituitary dysfunction after radiation for brain tumors. N Engl J Med 1993;328:87-94.

57 Livesey EA, Hindmarsh PC, Brook CG, et al. Endocrine disorders following treatment of childhood brain tumours. Br J Cancer 1990;61:622-5.

58 Follin C, Erfurth EM. Long-term effect of cranial radiotherapy on pituitaryhypothalamus area in childhood acute lymphoblastic leukemia survivors. Curr Treat Options Oncol 2016;17:50.

59 Magge SN, Goodman E, Armstrong SC. The Metabolic Syndrome in Children and Adolescents: Shifting the Focus to Cardiometabolic Risk Factor Clustering. Pediatrics 2017:140:e20171603-e12.

60 Gurka MJ, Filipp SL, DeBoer MD, et al. Geographical variation in the prevalence of obesity, metabolic syndrome, and diabetes among US adults. Nutr Diabetes 2018;8:14.

61 Nelson RA, Bremer AA. Insulin resistance and metabolic syndrome in the pediatric population. Metab Syndr Relat Disord 2010;8:1-14. 